\title{
Distribution of the chemical elements in the earth with some implications
}

\author{
LIN-GUN LIU \\ Research School of Earth Sciences, Australian National University, \\ Canberra, A.C.T., Australia
}

(Received April 13, 1982; accepted Augst 30, 1982)

\begin{abstract}
The distribution of chemical elements in the Earth's crust and its inferred interior is controlled mainly by the density periodicity of the elements, and is further perturbed by chemical affinity of the elements. The chemical elements have been classified into four major groups: heavy, medial, light and volatile, according to the physical and chemical properties and the distribution pattern of the elements. The light elements are generally enriched in the Earth's surface and the heavy elements are concentrated in its center. The abundances of most of the heavy and light elements increase and decrease respectively, very rapidly with increasing depth, whereas those for the medial and volatile elements remain relatively uniform throughout the Earth (except the core). Chemical affinity controls the abundances of the volatile and medial elements more than those of the light and heavy elements. On the basis of the principles of elemental distribution observed in the Earth, it is deduced that the chondrites were formed in an enviornment which experienced little gravitational influence, whereas the achondrites were formed under the influence of gravitation. The distribution of chemical elements in the Sun does not appear to be influenced by its gravitational field, which might be a consequence of nuclear fusion processes.
\end{abstract}

\section{INTRODUCTION}

The distribution of elements in the Earth is one of the primary objects of geochemical study, mainly owing to the work of GolDSCHMIDT (1.954) and to many others which followed.

A pretty reasonable knowledge regarding the distribution of chemical elements on the Earth's surface can be obtained (e.g. TAYLOR and MCLENNAN, 1981) owing to the availability of a vast number of analyses of chemical compositions of minerals and rocks in the various parts of the Earth's surface. No definitive solution of the radial distribution of chemical elements of the Earth is attainable because of the generally inaccessible nature of most of the interior. However, the available compositions of the surfaces of the Sun and other starts, the various meteorite types, and the Earth's and Moon's surface may yield clues to a solution, which may then be tested by means of the available geophysical, geochemical and cosmochemical data.

Available data for the chemical compositions of the continental crust and meteorites are the most reliable of all, followed by those of the oceanic crust, the lunar samples and the Sun. In conjunction with data for meteorites, attempts have been made in this paper to acquire from the compositions of the crust as much information as possible concerning the elemental distribution in the Earth, although the crust possesses less than 1 percent of the total mass or volume of the Earth.

\section{Cosmochemical Compositions}

The chemical compositions of the surfaces of the Sun and other stars are determined by analyses of radiation spectra. With the exception of a few very volatile elements, the chemical compositions of Type 1 carbonaceous chondrites (CI) are known to approximate most closely to those of the Sun. The good correlation between them is normally exhibited in a logarithmic plot of abundances $v s$. abundances for the elements of these two types of body. A linear correlation with nearly a unit slope is 
found. In this paper, I have chosen to plot the logarithmic ratios of the abundances of the elements against the atomic number (see Fig. 1). Such a plot has many advantages over the conventional plots of abundances vs. abundances. Should the abundances of the chemical elements of the Sun or CI chondrites somehow relate to their physical and/or chemical properties, the correlation between the abundances and physical and/or chemical properties might be revealed in a plot of abundance $v s$. atomic number, since both physical and chemical properties of the elements are periodic functions of atomic number. I shall return to this point and demonstrate its merits in the next section.

The abundances of elements of a CI chon- drite relative to those of the Sun are plotted against the atomic number in Fig. 1. There are many recent estimates or compilations of the chemical compositions of CI chondrites in the literature, e.g. WASSON (1974), SMITH (1977) and MASON (1979). The compositions of Orgueil (CI) (except for ${ }_{4} \mathrm{Be},{ }_{5} \mathrm{~B},{ }_{41} \mathrm{Nb},{ }_{45} \mathrm{Rh}$ and ${ }_{64} \mathrm{Gd}$ which are estimates of TAYLOR (1980)) compiled by Mason (1979) are used in this work. Two sets of the compositions of the Sun estimated respectively by SUESS and UREY (1956) and Ross and Aller (1976) were used. Data for ${ }_{11} \mathrm{Na},{ }_{12} \mathrm{Mg},{ }_{16} \mathrm{~S}$ and ${ }_{20} \mathrm{Ca}$ in Ross and AlLER (1976) are replaced by those of HoLwEGER (1977). There are many other estimates such as those of CAMERoN (1973) which

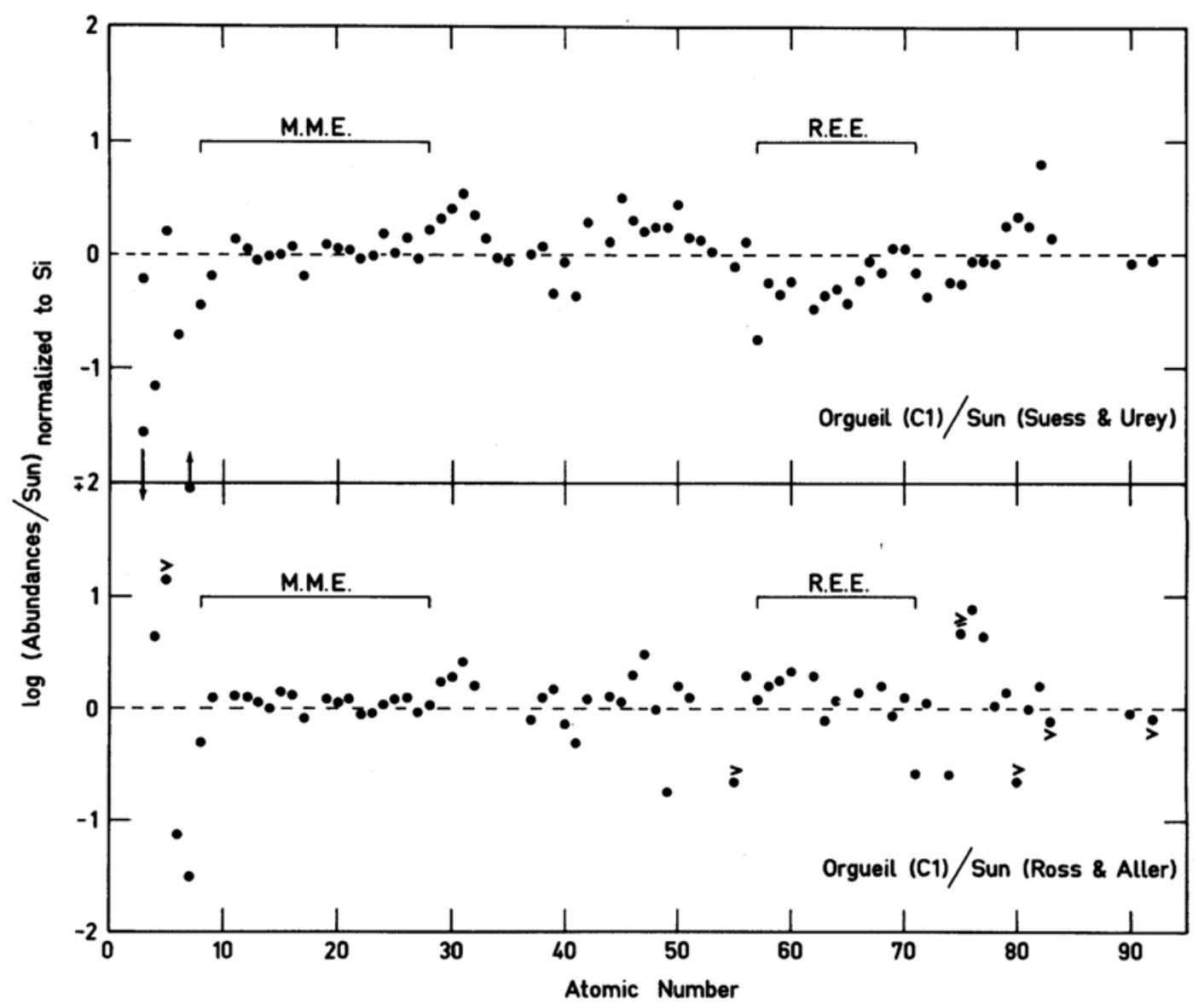

Fig. 1. The abundances of chemical elements of a CI chondrite (Orgueil) relative to those of the sun (normalized to silicon) are plotted against the atomic number. 
are available in the literature. Figure 1 shows that the differences between the two sets of data for the Sun are negligibly small. With the exception of those elements having atomic numbers smaller than ${ }_{8} \mathrm{O}$ and of the inert gases, the abundances of elements of the Orgueil chondrite

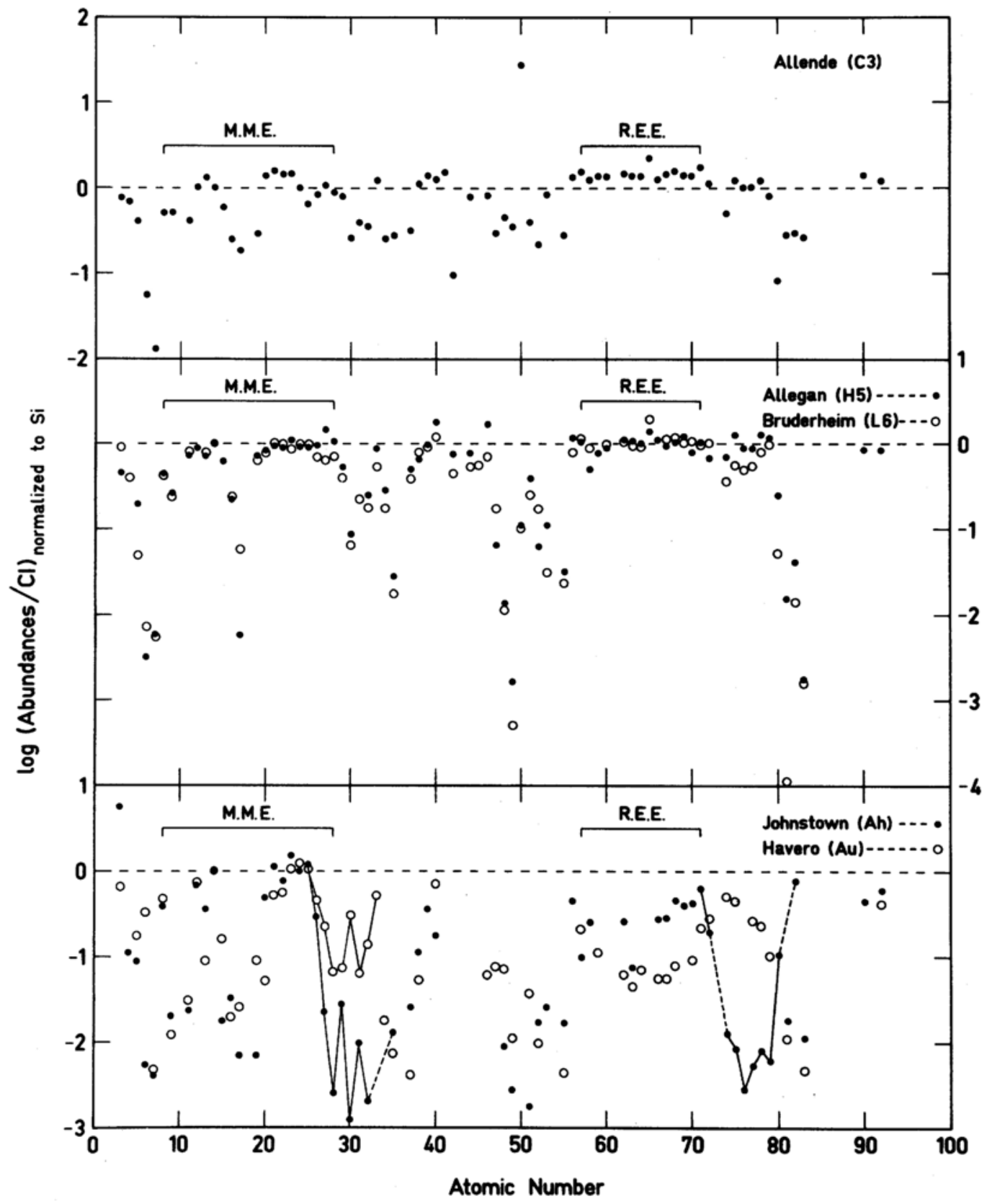

Fig. 2. The CI and silicon normalized compositions of a Type 3 carbonaceous chondrite (Allende), two ordinary chondrites (Allegan and Bruderheim) and two achondrites (Johnstown and Havero) are plotted against the atomic number. The solid and dashed lines connecting some adjacent elements of the achondrites are used to aid analysis. For details, refer to the contents under the section "Implications for Cosmophysical Environments". 
never deviate from those of the Sun more than by a factor of 8 . Amongst the major and minor elements of the Earth (M.M.E.) indicated in Fig. 1, ${ }_{8} \mathrm{O}$ in Orgueil chondrite deviates most from that of the Sun, by a factor of 2 to 3 (depleted). All the other M.M.E. deviate from the Sun by less than 50 percent. The major elements ${ }_{12} \mathrm{Mg},{ }_{13} \mathrm{Al},{ }_{14} \mathrm{Si},{ }_{20} \mathrm{Ca}$ and ${ }_{26} \mathrm{Fe}$ are within 30 percent. Because of this close correlation, and becuase the abundances of the elements of CI chondrites are better determined, it is a common practice and a preference for geochemists to use the data for CI chondrites as representative of the volatile-depleted solar abundances of the elements.

In Fig. 2, I have chosen to show the abundances of elements (relative to $\mathrm{CI}$ ) of a Type 3 carbonaceous chondrite (Allende), two ordinary chondrites (Allegan and Bruderheim) and two achondrites (Johnstown and Havero). The choice is not entirely arbitrary, since more complete data for these meteorites are available than for others. The chemical data for all these meteorites are from the compilation of MASON (1979). With the exception of ${ }_{50} \mathrm{Sn}$ in Allende, the abundances of elements in all these meteorites might be interpreted as due to a variety of degrees of differentiation of the CI chondrites. Type 3 carbonaceous chondrite deviates the least, and the achondrites deviate the most from the CI chondrites. However, the oxygen isotope data of, eg., Clayton $(1978,1981)$ clearly reveal that they come from different chemical reservoirs. With the exception of achondrites, however, little correlation between the abundances of elements and the atomic number is revealed in these meteorites. Some of the elements in the achondrites are connected by solid and dashed lines in Fig. 2, which will be discussed later.

\section{Principles of Elemental Distribution}

The abundances and distribution of chemical elements in the Earth are most likely determined by the following factors: (1) primordial abundances of the elements; (2) chemical affinity between the elements to form stable compounds or alloys; and (3) volatility and density of the elements or the compounds. Thus, (2) and (3) are respectively the chemical and physical processes which control the distribution of the chemical elements of the Earth. Both temperature and pressure should, in turn, have a decisive influence on factors (2) and (3).

The effect of the primordial abundances may be eliminated by considering the abundances of the Earth rleative to the solar abundances, or more accurately the CI abundances. This is a general practice adopted by geochemists. At least, the Oddo-Harkins regularity* could be mostly removed by such an approach. I have also adopted such a method throughout this work. However, any error introduced by such an approach would, in principle, be revealed later if the observed abundances in the Earth's surface and the inferred abundances in its interior, could not be satisfactorily explained by the chemical and physical processes which have modified the primordial abundances to yield the present-day abundances, providing that the chemical and physical processes are fully understood.

FActor (2) and the volatility of factor (3) would correspond most closely to the factors of geochemical affinity and temperature respectively put forward by GoLDSCHMIDT (1937) and several of his earlier publications. However, density of the elements or compounds appear to have little significance in Goldschmidt's principles of the distribution of the chemical elements, which have since been, more-or-less, strictly followed by geochemists for more than a half century. Following Goldschmidt's concepts, MASON (1966) stated the following:

It is highly significant that the distribution of elements in a gravitational field, such as that of the Earth, is controlled not by their densities or atomic weights, as might perhaps be expected, but by their affinities for the 
major phases that can be formed. This is, in turn, controlled by the electronic configurations of their atoms. For example, uranium and thorium, although of high density, are strongly electro-positive elements and have concentrated in the Earth's crust as oxides or silicates. Gold and platinum metals, on the other hand, have no tendency to form oxides or silicates, and alloy readily with iron; hence they are presumably concentrated in the Earth's core. The distribution of the elements is not directly controlled by gravity, which merely controls the relative positions of the (major) phases; the distribution of the elements within these phases depends upon chemical potentials.

In contrast with this statement, I shall later demonstrate that the density of an element plays at least an equal, if not a more, important role than that of chemical affinity in the distribution of the elements in the Earth.

On the basis of observations of the chemical abundances of meteorites and of certain metallurgical products, GolDSCHMIDT $(1922,1923)$ first grouped the elements of the Earth into 4 categories: siderophile, chalcophile, lithophile and atmophile (there is also the fifth one, of less interest here, of biophile). With the exception of atmophile, the characterisation of elements in the first three categories is determined primarily on the basis of their chemical affinity for iron, sulfur and silicate, respectively. Goldschmidt's classification leaves no room for density as a factor in the radial distribution of the chemical elements of the Earth, except that the siderophiles might have alloyed with iron which sank toward the center to form the Earth's metallic core.

There are other classifications of elements which are commonly used by geochemists. Terms like compatible, moderate-compatible, incompatible, volatile, less-volatile, non-volatile, early-condensate $\ldots$ are extensively used throughout the geochemical literature. I will avoid use of most of this terminology in my discussion of the elemental distribution in the
Earth.

\section{Elemental Abundances on the EARTH'S SURFACE}

Continental crust Although the bulk composition of the continental crust may be somewhat uncertain, its chemical composition is the best determined of all the components of the Earth. There are many different estimates in the literature, but a complete list of most of the chemical elements is rare. I have chosen the older MASON (1966) estimate along with the recent estimate by TAYLOR and MCLENNAN (1981). From the available data shown in Fig. 3 (b), it is clear that the two estimates agree with each other well within their uncertainties. As noted, there is no single rock type known to possess this chemical composition on the Earth or anywhere in the solar system. Recently, the abundances of the major and minor elements of the continental and oceanic crusts were thoroughly investigated by RoNOv and YAROSHEVSKY (1976). In the literature, there are also many estimates of the chemical composition of the whole crust, e.g., SHaw (1972) and SMITH (1977). I would prefer to discuss the continental and oceanic crusts separately because of their different status and origin.

A distinct feature that stands out in the abundance pattern of Fig. 3(b) is that the abundances of the chemical elements in the continental crust are a strong periodic function of atomic number (if the volatile elements are neglected). However, these features would not be so distinct if the primordial abundances were not obviated, or if the volatile and the shortlived radioactive elements were all included. It is even more striking when the abundance pattern of Fig. 3(b) is compared with the density periodicity of the elements shown in Fig. 3 (a). The densities of the elements are those for the stable solid and liquid forms at room temperature and 1 atmospheric pressure, as used in LIU (1973). Although the abundance pattern of the continental crust is not an exact mirror image of the density periodicity of the element, 


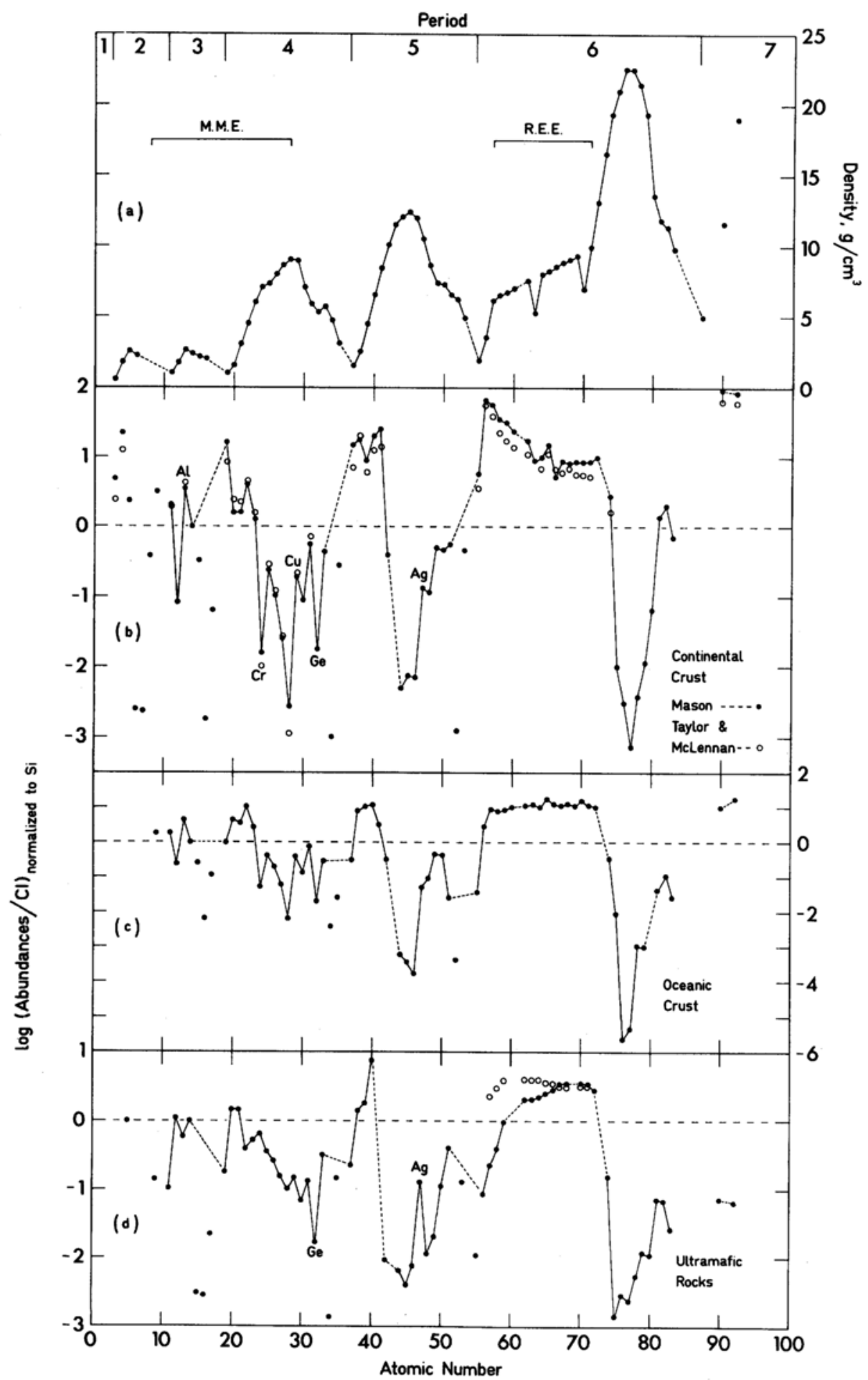

Fig. 3. The CI and silicon normalized compositions for the continental crust (b), oceanic crust (c), and ultramafics (d) are compared with the density periodicity (a) of chemical elements. For details refer to the text. 
the close correlation between them should provide us some insight into the distribution of the chemical elements of the Earth. Both the physical and chemical properties of an element are controlled to a large extent by the nature of the outermost electrons, and the electron configuration for the outermost shell of an element is a strongly periodic function of its atomic number. Thus, the close correlation between the normalized abundance of the elements, which is in turn controlled by the physical and chemical properties of the elements, and their densities, is not entirely unexpected.

The solid and dashed lines connecting the adjacent elements are used to aid the analysis of the diagram. The dashed lines were used where data are missing or occupied by volatile and short-lived radioactive elements. Detailed discussion of the volatile elements is pursued below. Combining the features of Figs. 3 (a) and $3(\mathrm{~b})$, it is clear that the chemical elements of the continental crust are gravitationally differentiated according to their density periodicity (not the absolute values of their density) in the Periodic Table. In other words, for the continental crust, the CI normalized abundances of the chemical elements are generally depleted and the densities of the elements increase in the same manner as the order of the Period increases. The fact that the elements are differentiated according to the density periodicity and not to their absolute densities is a manifestation of the presence of the other important factor of chemical affinity. Furthermore, the abundances of chemical elements in the same Period are approximately inversely proportional to their densities. Thus, the light elements of the first (IA) and the second Group (IIA) of the Periodic Table are relatively enriched in the continental crust and the heavy elements of the third Period ${ }_{12} \mathrm{Mg},{ }_{13} \mathrm{Al}$ and $\left.{ }_{14} \mathrm{Si}\right)$, the fourth Period ${ }_{24} \mathrm{Cr}$, ${ }_{25} \mathrm{Mn},{ }_{26} \mathrm{Fe},{ }_{27} \mathrm{CO},{ }_{28} \mathrm{Ni}$ and ${ }_{29} \mathrm{Cu}$ ), the fifth Period $\left({ }_{42} \mathrm{Mo},{ }_{44} \mathrm{Ru},{ }_{45} \mathrm{Rh},{ }_{46} \mathrm{Pd}\right.$ and ${ }_{47} \mathrm{Ag}$ ), and the sixth Period $\left({ }_{74} \mathrm{~W},{ }_{75} \mathrm{Re},{ }_{76} \mathrm{Os},{ }_{77} \mathrm{Ir},{ }_{78} \mathrm{Pt}\right.$ and $\left.{ }_{79} \mathrm{Au}\right)$ are depleted (see Table 2). Note that the lanthanides or rare earth elements (R.E.E.) and the actinides of ${ }_{90} \mathrm{Th}$ and ${ }_{92} \mathrm{U}$ are not heavy elements of their respective elemental periods. However, there is little doubt that the chemical affinity for silicates has also contributed to the great abundances of these elements in the continental crust. Abundances of $U$ and $T h$ in the various parts of the Earth have also been discussed in length elsewhere (LiU, 1982). Note also that the nearly mirror image between the abundance and density patterns for the general trend from light R.E.E. to heavy R.E.E. is striking, since these elements possess nearly identical chemical affinity for whatever major phases are involved.

All deviations from the above general tendency may be interpreted as resulting from the perturbations due to the chemical affinity of the individual elements to form stable solid phases, especially silicates and oxides. The worst correlation between the density and abundance patterns of Figs. 3 (a) and 3 (b) exists in the third and fourth Periods. However, there are only a few elements which display a poor correlation. These are ${ }_{13} \mathrm{Al}$ of the third Period and ${ }_{24} \mathrm{Cr},{ }_{29} \mathrm{Cu}$ and ${ }_{32} \mathrm{Ge}$ of the fourth Period. ${ }_{13} \mathrm{Al}$ and ${ }_{29} \mathrm{Cu}$ are enriched and ${ }_{24} \mathrm{Cr}$ and ${ }_{32} \mathrm{Ge}$ are depleted compared with the general abundance pattern. Note that the abundances of these elements completely contradict the OddoHarkins rule. The enrichment of ${ }_{13} \mathrm{Al}$ in the crust may be related to the upward-movement of the light elements of the first (IA) and second (IIA) Groups. These elements are light and their sizes are large. Of course, the two properties are related to each other. The large size of these elements requires a rather open-packed structure type possessing the corner-shared $\left(\mathrm{SiO}_{4}\right)^{4^{-}}$tetrahedra. Feldspars are of typical structures possessing corner-shared tetrahedra. All silica framework or chain structures resulting from joined $\left(\mathrm{SiO}_{4}\right)^{4-}$ end up with an even number of charges. Thus, $(\mathrm{NaAl})^{4+},(\mathrm{KAl})^{4+}, \ldots$ would suit the silica frameworks or chains more readily than $4 \mathrm{Na}^{+}, 4 \mathrm{~K}^{+}, \ldots$ because there are a limited number of sites in the frameworks or chains available for these many large cations, whilst electrical neutrality has to be maintained. The feldspar structure can accommodate the large IA and IIA elements only if a small trivalent cation such as 
Table 1. The ratios of some heavy elements to magnesium (in weight) for both the continental and oceanic crusts

\begin{tabular}{ccccc}
\hline Period & Element & Continent & Ocean & Continent/Ocean \\
\hline 4 & $\mathrm{Co}$ & $1.2 \times 10^{-3}$ & $1.0 \times 10^{-3}$ & 1.20 \\
& $\mathrm{Ni}$ & $3.6 \times 10^{-3}$ & $2.9 \times 10^{-3}$ & 1.23 \\
& $\mathrm{Ru}$ & $4.8 \times 10^{-7}$ & $2.2 \times 10^{-8}$ & 22 \\
5 & $\mathrm{Rh}$ & $2.4 \times 10^{-7}$ & $4.3 \times 10^{-9}$ & 55 \\
& $\mathrm{Pd}$ & $4.8 \times 10^{-7}$ & $4.3 \times 10^{-9}$ & 110 \\
& $\mathrm{Re}$ & $4.8 \times 10^{-8}$ & $1.6 \times 10^{-8}$ & 3 \\
6 & $\mathrm{Os}$ & $2.4 \times 10^{-7}$ & $6.5 \times 10^{-11}$ & 3700 \\
& $\mathrm{Ir}$ & $4.8 \times 10^{-8}$ & $1.1 \times 10^{-10}$ & 440 \\
& $\mathrm{Pt}$ & $4.8 \times 10^{-7}$ & $5.0 \times 10^{-8}$ & 10 \\
\hline
\end{tabular}

$\mathrm{Al}$ is present. ${ }_{29} \mathrm{Cu}$ has the second highest tendency to react with the volatile element ${ }_{16} \mathrm{~S}$ to form sulfide or sulfate, which may have reusited in the enrichment of $\mathrm{Cu}$ in the crust. Note that ${ }_{47} \mathrm{Ag}$ of the fifth Period is also more enriched in the crust than its adjacent elements having even atomic numbers. It is well known that $\mathrm{Ag}$ possesses the highest chalcophile tendency. The depletion of $\mathrm{Cr}$ and $\mathrm{Ge}$ in the crust may be associated with the formation of the iorn core of the Earth. According to Goldschmidt (1954), $\mathrm{Ge}$ has very strong tendency to alloy with $\mathrm{Fe}$ whereas, in the presence of metallic $\mathrm{Fe}, \mathrm{Cr}$ has strong affinity for FeS. Thus, Ge and perhaps $\mathrm{Cr}$ may have been extracted into the core. It should be pointed out that ${ }_{28} \mathrm{Ni}$ is also somewhat depleted in the continental crust as would be expected from its density, compared with the abundances of the heavy elements of the fifth and sixth Periods. More discussion of these elements shall be presented later.

It should, of course, be borne in mind that most of the chemical elements in the Earth do not exist as discrete phases composed of a single element. This is especially true for the M.M.E. and the light elements of the IA and IIA Groups. In this case, however, the heavy M.M.E. form silicates or oxides having densities still greater than those of the light ones. On the other hand, the status of the trace elements, especially those for the heavy elements of the fifth and sixth Periods, is somewhat uncertain. They may exist as submicroscopic metal grains or atomic clusters, or as ions, substitutional or interstitial, in the major or minor mineral phases. I have attempted to compare the "ionic density"* for the chemical elements with the abundance pattern. Several difficulties were encountered, however: first, the ionic radii of the "elements" are not well defined; second, the ionic radii vary with both the valence state and coordination number; and thirdly, the elements ${ }_{7} \mathrm{~N},{ }_{6} \mathrm{C},{ }_{5} \mathrm{~B},{ }_{15} \mathrm{P},{ }_{14} \mathrm{Si}, \ldots$ possess the greatest "ionic density" yet show no correspondence with the abundance pattern.

According to MASON (1966), the marked correlation between the geochemical affinity (but not the degree of affinity or of abundance) and the volume periodicity (reciprocal to the density periodicity shown in Fig. 3(a)) of the chemical elements was noticed by GoLDSCHMIDT. GolDSCHMIDT noted that all siderophile elements are near the minima (corresponding to the maxima in Fig. 3(a)); the chalcophile elements fall on the right limbs of the minima, followed by the atmophile elements; and the lithophile elements are near the maxima or on the right limbs of the maxima. This is very close to my observation of Figs. 3 (a) and 3 (b), but GoLDSCHMIDT attached no significance to the volume periodicity and the abundances of the chemical elements in the Earth's crust.

Oceanic crust The abundances of the chemical elements of the oceanic crust, or average oceanic basalts, relative to the CI abun-

* The ionic density of an element is defined as its atomic weight divided by the cube of its ionic radius. 
dances are exhibited in Fig. 3 (c). Note that the abundance scale of the oceanic crust has been condensed by a factor of 2 compared with that of Fig. 3(b). The abundance data for the oceanic crust are mostly from S. R. TAYLOR (1981, pers. com.) except for the following: ${ }_{25} \mathrm{Mn}$ from BCR-1, ${ }_{32} \mathrm{Ge},{ }_{34} \mathrm{Se},{ }_{35} \mathrm{Br},{ }_{46} \mathrm{Pd},{ }_{47} \mathrm{Ag}$, ${ }_{48} \mathrm{Cd},{ }_{49} \mathrm{In},{ }_{51} \mathrm{Sb},{ }_{52} \mathrm{Te},{ }_{75} \mathrm{Re},{ }_{76} \mathrm{Os},{ }_{77} \mathrm{Ir},{ }_{79} \mathrm{Au},{ }_{81} \mathrm{Tl}$ and ${ }_{83} \mathrm{Bi}$ from the average of analyses for 5 fresh mid-ocean ridge basalts by HeRTOGEN et al. (1980); and ${ }_{33} \mathrm{As},{ }_{42} \mathrm{Mo},{ }_{45} \mathrm{Ru},{ }_{50} \mathrm{Sn},{ }_{74} \mathrm{~W}$ and ${ }_{78} \mathrm{Pt}$ from compilations of CHOU (1978). As in the continental crust, the light and volatile elements will be discussed in a later section.

Figure 3(c) shows that the correlation between the abundance and density periodicity of the chemical elements for the oceanic crust is even more prominent than that for the continental crust. The abnormality for the elements of the third and fourth Periods ( $\mathrm{Al}, \mathrm{Cu}, \mathrm{Cr}$ and $\mathrm{Ge}$ ) due to geochemical affinity still stands out as in the case of the continental crust. In comparison with the continental crust, however, there are two important features which are characteristic of the oceanic crust. First, the heavy elements of the fifth and sixth Periods are respectively about 100 and 1,000 times more depleted in the oceanic compared with the continental crust, whereas the abundances of the heavy elements of the third and fourth Periods are nearly the same for both the oceanic and continental crusts. Second, the abundance pattern for R.E.E. in the oceanic crust is nearly independent of or slightly increases with the density periodicity, which is very different from the trend displayed by the continental R.E.E. periodicity. The latter feature is well known to geochemists.

It appears that the similar abundance patterns of the elements of the fourth Period for the continental and oceanic crusts result from the same event in the past before the formation of the continental and oceanic crusts. This is suggested because there is a general agreement that the mean age of the continental crust ( $\sim 2.5$ b.y.) is much older than that of the oceanic ( $\sim 0.2$ b.y.). Thus, the fork-shaped pattern of the elemental abundances of the fourth Period common to both the continental and oceanic crusts is probably the relict of that event. From the known properties of the Earth, it is conceivable that this event was most likely the formation of the metallic core which extracted most of these elements at nearly the same time and by about the same amount. On

Table 2. The geological classification of the elements in relation to the periodic table

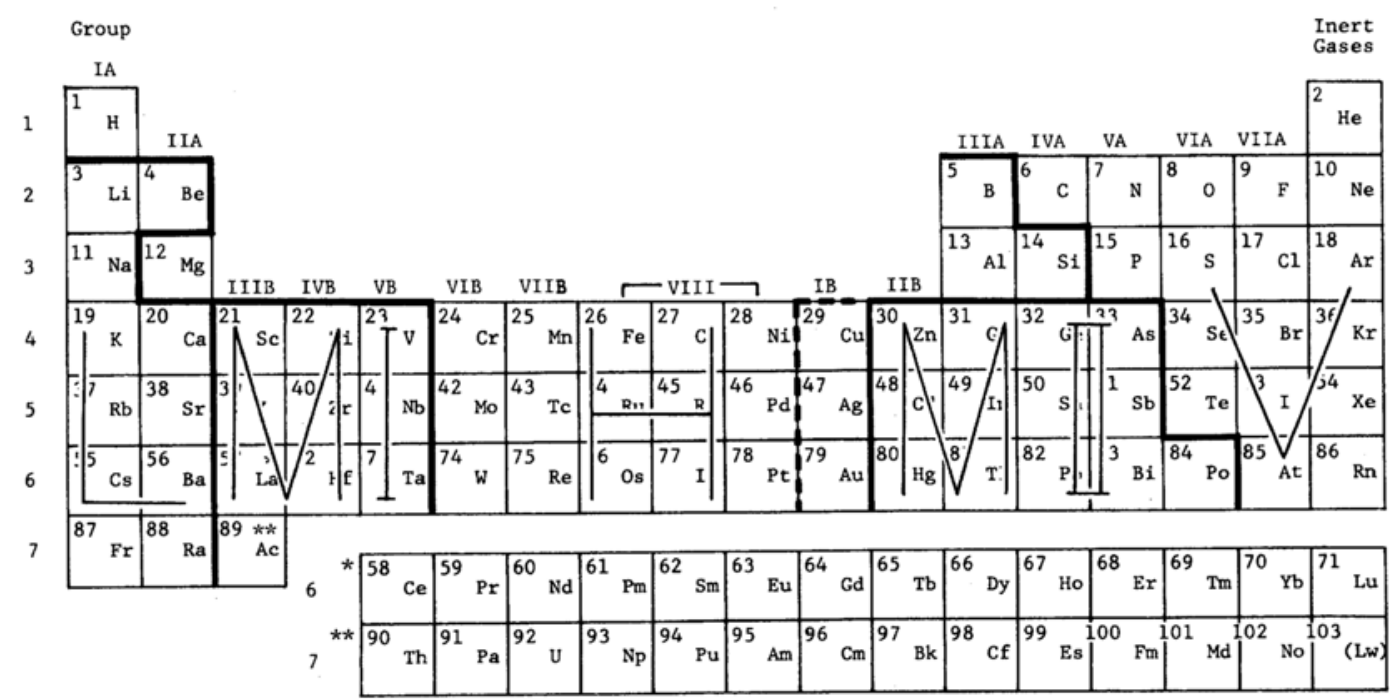


the other hand, the two orders and three orders of magnitude depletion of the heavy elements of the fifth (e.g. Ru, Rh, Pd) and sixth (e.g. Re, $\mathrm{Os}, \mathrm{Ir}, \mathrm{Pt}$ ) Periods, respectively, of the oceanic crust relative to the continental crust are not reconcilable with GoLDSCHMIDT's geochemical affinity for core-forming iron. Comparing the average ages of the continental and oceanic crusts, it is conceivable that the oceanic crust has been recycled through the mantle, by convection, more often than the continental crust. It is conceivable that slow mantle convection would, in all probability, accelerate the separation of the heavy elements from the light ones in a gravitational field. Thus, the more the crust recycles through the mantle by convection, the more depleted these heavy elements become. This would qualitatively account for the nearly 100 -fold and 1,000-fold depletion of these heavy elements in the oceanic crust than in the continental crust.

Two processes, partial melting and convection, involve recycling of crustal material. According to current concepts, partial melting of mantle material forms the crust, especially the oceanic crust. Thus, the heavy elements may concentrate in the underlying refractory mantle (or even go all the way to the core). This would normally be regarded as "partitioning" due to chemical affinity by most geochemists and petrologists. However, it is my opinion that the partitioning of these heavy elements in the restite material is primarily due to gravitational separation, because there is no appreciable amount of free iron in the system of the crust and mantle, and the elements in question are socalled "siderophiles". In fact, the total iron content of the average continental and oceanic crust is higher than that of average ultramafic nodules, which are generally believed to represent upper mantle material. The enrichment of iron in the crust is most likely to be related to chemical affinity, in my view.

Although the abundance pattern of the elements of the fourth Period for the continental and oceanic crusts are generally similar, some differences in details may still be significant.
Nickel is the most dense and "siderophile" element of the Period. The partitioning of $\mathrm{Ni}$ between restite crystals and silicate melt during partial melting has received considerable attention (e.g. TAYLOR et al., 1969; HEDGE, 1971) and experimental studies (e.g. HÄKLI and Wright, 1967; NABELEK, 1980). Nickel is found by experiment to be enriched in the restite crystals compared with the melt. However, is $\mathrm{Ni}$ enriched through chemical affinity or gravitationally concentrated in the refractory material, which is always settled at the bottom of the experimental container? According to this study, I would suggest that the enrichment of $\mathrm{Ni}$ in the solid residual material is at least partially due to gravitational concentration. Nevertheless, $\mathrm{Ni}$ may substitute for $\mathrm{Mg}$ in the restite crystals owing to their similar size and charge. The oceanic crust contains more $\mathrm{Mg}$ than the continental crust. If chemical substitution alone controls the distribution of $\mathrm{Ni}$, then the $\mathrm{Ni} / \mathrm{Mg}$ ratio in the oceanic crust should be greater than, or at least equal to, that of the continental crust. However, the exact opposite relation between them is found (see Table 1). Since the mean age of the continental crust is much greater than that of the oceanic crust, one may conclude that the $\mathrm{Ni}$ content of the mantle has decreased during the evolution of the Earth. This can best be explained by the process of slow convection of the mantle which has previously been invoked to account for the abundance patterns of the other heavy elements of the fifth and sixth Periods for the oceanic crust, i.e. the heavy elements are depleted according to their density periodicity. The ratios of some heavy elements to magnesium (in weight) for both the continental and oceanic crusts are listed in Table 1, which shows that the continental crust is relatively enriched in all of these elements compared with the oceanic crust. The degree of enrichment increases with the increasing period of the Periodic Table. One might wish to attribute the enrichment of $\mathrm{Ni}$ in the continental crust to chemical substitution for $\mathrm{Mg}$, but then $\mathrm{Co}$ and other heavy elements of the fifth and sixth Periods, which are not chemically so closely 
related to magnesium are still enriched. On the other hand, the single process of gravitational separation according to density periodicity can account for all of these features.

The high concentration of $\mathrm{Ni}$ in the Archaean basalts of equivalent major element chemistry to the present oceanic crust observed by BENCE et al. (1981) can easily be accounted for by the present study. In addition to $\mathrm{Ni}$, this study also suggests that all the other heavy elements, such as those listed in Table 1, would be enriched in these Archaean basalts as well. Only limited abundance data for heavy elements, such as $\mathrm{Pd}, \mathrm{Ir}$ and $\mathrm{Pt}$, in the Archaean basalts are available in the literature (CHOU, 1978; CROCKET, 1981), but these data are in line with the present prediction.

Ultramafics These are the rocks and nodules occurring on the Earth's surface, but believed to be representative of material from the mantle down to a depth of $200 \mathrm{~km}$ or so. Our knowledge of the abundance distribution of chemical elements decreases drastically in the order continental crust $>$ oceanic crust $>$ ultramafics, since there are problems of incomplete sampling, incomplete analysis, and contamination by country rocks by or through which the ultramafics were brought up.

The data used in Fig. 3(d) of this work are from compilations of TUREKIAN and WEDEPOHL (1961), Goles (1967), RINGWOOD and KESSON (1977) and CHOU (1978) and some recent data by JAGOUTZ et al. (1979) and MoRGAN et al. (1981). Two sets of data for R.E.E. are shown, representing the extremes of the abundance trend measured by JAGOUTZ et al. (1979).

Although it is more irregular, owing partially to less reliable data, the abundance pattern for the chemical elements of the ultramafics still shows a reasonable correlation with the density periodicity of the chemical elements, but the degree of impoverishment of the heavy elements is similar to that found in the continental crust rather than in the oceanic crust. However, it perhaps should be borne in mind that nearly all the samples of ultramafics, from which the abundance data of Fig. 3(d) were obtained, come from continental areas. For example, of the various samples from 14 different localities measured by JAGOUTZ et al. (1979) and MORGAN et al. (1981) all but one come from continental areas. Since these nodules have been trapped in the continental crust, they cannot recycle through the mantle by convection as often as the oceanic crust does. Based on $\mathrm{Sr}$ isotope data for clinopyroxene in their samples, JAGOUTZ et al. (1979) have reported that these peridotite samples may have been in a closed system for more than 3.6b.y. Thus, it is not surprising that both the continental crust and the ultramafics bear some common features of their abundance patterns of the heavy elements. This also, in turn, poses not only problems of whether the chemical composition of these ultramafics is representative of the subcontinental mantle and the mantle below oceanic crust as well, but also problems of whether the composition of these ultramafics is representative of the present-day mantle (or at least of the same age of the present-day oceanic crust) or whether they are relicts of the mantle at the time these ultramafics were brought up. The reader should be aware of the major difference of interpretation of the abundance pattern of the heavy elements between the ultramafics and the oceanic crust presented in this study compared with hypotheses ascribing relative enrichment of the heavy elements in the ultramafics to a later meteorite bombardment on the Earth currently under discussion by e.g. CHOU (1978) and MORGan et al. (1981).

The only exception of the 14 localities cited is the one from Salt Lake Crater, Hawaii, which is generally regarded as a typical "hot spot" on the Earth's surface. It is a widely accepted concept that the position of a "hot spot" is immobile relative to the continental and oceanic crusts. Mantle convection, especially under the oceanic crust, is also a well accepted concept. It is conceivable, therefore, that the source material of the hot spot may be generated from a region somewhere inside of the mantle, but free from convection. There are several possible 
source regions for the hot spot which have been postulated in the literature (MORGAN, 1972; WILSON, 1973; LeEDS et al. 1974; SUN and HANSON, 1975; ANDERSON, 1975, and many others). Regardless of the various speculations, however, one thing is in common, i.e., the sources in all the models are free from convection. This would account for the rather similar abundance pattern for the heavy elements between the ultramafics from continental areas and from the hot spots, both do not recycle through the mantle convection as often as the oceanic crust. This would also suggest that studies of the chemical compositions of ultramafic nodules from mid-ocean ridges, or alternatively, the tectonized peridotite/harzburgite basal layers of ophiolites should be more informative for the compositions of the mantle.

The fork-shape abundance pattern for the fourth Period elements observed in both the continental and oceanic crusts is not prominent in the ultramafics. This is mainly due to the enrichment, relative to the crust, of ${ }_{24} \mathrm{Cr}$ and ${ }_{28} \mathrm{Ni}$ in the ultramafics, which is, however, normal rather than an exception, according to the density periodicity. Thus, it appears that the impoverishment of these two elements in both the continental and oceanic crusts is not due to extraction by iron into the core. According to GoLDSCHMIDT (1937), Cr has strong affinity for silicates and $\mathrm{Ni}$ readily substitutes for $\mathrm{Mg}$ in the crystals of ferromagnesium silicates. Since $\mathrm{Cr}$ is strongly depleted in the silicate crust but not in the ultramafics, it is suggested that the impoverishment of $\mathrm{Cr}$ in the crust is the result of chemical association with $\mathrm{Mg}$, which is the only major element depleted in both continental and oceanic crust, but not in the ultramafics. On the basis of the abundance patterns shown in Fig. 3, it appears that ${ }_{30} \mathrm{Zn}$ and ${ }_{32} \mathrm{Ge}$ are the only two elements which are depleted in the Earth's surface, and might have been extracted by iron into the core owing to their siderophile affinity.

The enrichment, or more correctly the normal abundance, of $\mathrm{Cr}$ in the ultramafics may bear some significance for the light component of the outer core, of which detailed discussion is given elsewhere ( $\mathrm{LIU}$, in preparation). According to GoldschmidT (1954), ${ }_{23} \mathrm{~V},{ }_{24} \mathrm{Cr}$ and ${ }_{25} \mathrm{Mn}$ have storng chemical affinities for $\mathrm{FeS}$ rather than $\mathrm{Fe}$, if free iron is present, as in the case of the core. With the exception of $\mathrm{Cr}$ in the crust, for the reasons given above, these three elements are not strongly depleted in crust and ultramafics (or the mantle?). The degree of depletion of all three elements is generally in harmony with their relative positions according to the density periodicity. This may indicate that these elements have never been in contact with $\mathrm{FeS}$, while free iron was sinking to form the core, or that there never has been a large amount of FeS existing in the Earth. The latter implies that $\mathrm{S}$ may not be a primary light component of the Earth's core.

All the light elements of IA and IIA Groups are depleted in the ultramafics, as would be expected from their relative densities, but more discussion is given below. The abundance trends (increases with increasing atomic number or density) of the R.E.E. in the ultramafics appear to reflect the removal of these elements by gravitational separation into the continental crust.

Volatile and light elements Discussion of the volatile and light element abundances in the crust and ultramafics has been deliberately avoided in the previous sections, because there exist some common characteristics of these elements in the crust and ultramafics, and also because, to some extent, the data for these elements are less reliable than those for other elements previously discussed. The latter is particularly true for the volatile elements.

According to the abundance pattern and the physical and chemical characteristics of these elements, I have grouped the inert gases and all the elements of Groups VIIA and VIA (except ${ }_{84} \mathrm{Po}$ ), ${ }_{7} \mathrm{~N}$ and ${ }_{15} \mathrm{P}$ of Group VA, ${ }_{6} \mathrm{C}$ of Group IVA, and ${ }_{1} \mathrm{H}$ of Group IA as volatile elements; and all the elements of Groups IA and IIA (except ${ }_{1} \mathrm{H}$ and ${ }_{12} \mathrm{Mg}$ ) as light elements (see Table 2 ). It is obvious that the classification is some- 
what arbitrary, but the elements of the same class do possess common characteristics.

The abundance pattern vs. the density for the assumed gaseous state (STP) of the volatile elements is displayed in Fig. 4. Data sources for all the volatile elements in the continental crust;
${ }_{35} \mathrm{Br},{ }_{34} \mathrm{Se},{ }_{52} \mathrm{Te}$ and ${ }_{15} \mathrm{P}$ in the oceanic crust; and ${ }_{9} \mathrm{~F},{ }_{17} \mathrm{Cl},{ }_{35} \mathrm{Br},{ }_{53} \mathrm{I},{ }_{16} \mathrm{~S},{ }_{34} \mathrm{Se},{ }_{52} \mathrm{Te}$ and ${ }_{15} \mathrm{P}$ in the ultramafics have been given before. ${ }_{9} \mathrm{~F},{ }_{17} \mathrm{Cl}$ and ${ }_{16} \mathrm{~S}$ in the oceanic crust are from MOORE and FABBI (1971) and compilations of RINGwOOD and KESSON (1977).

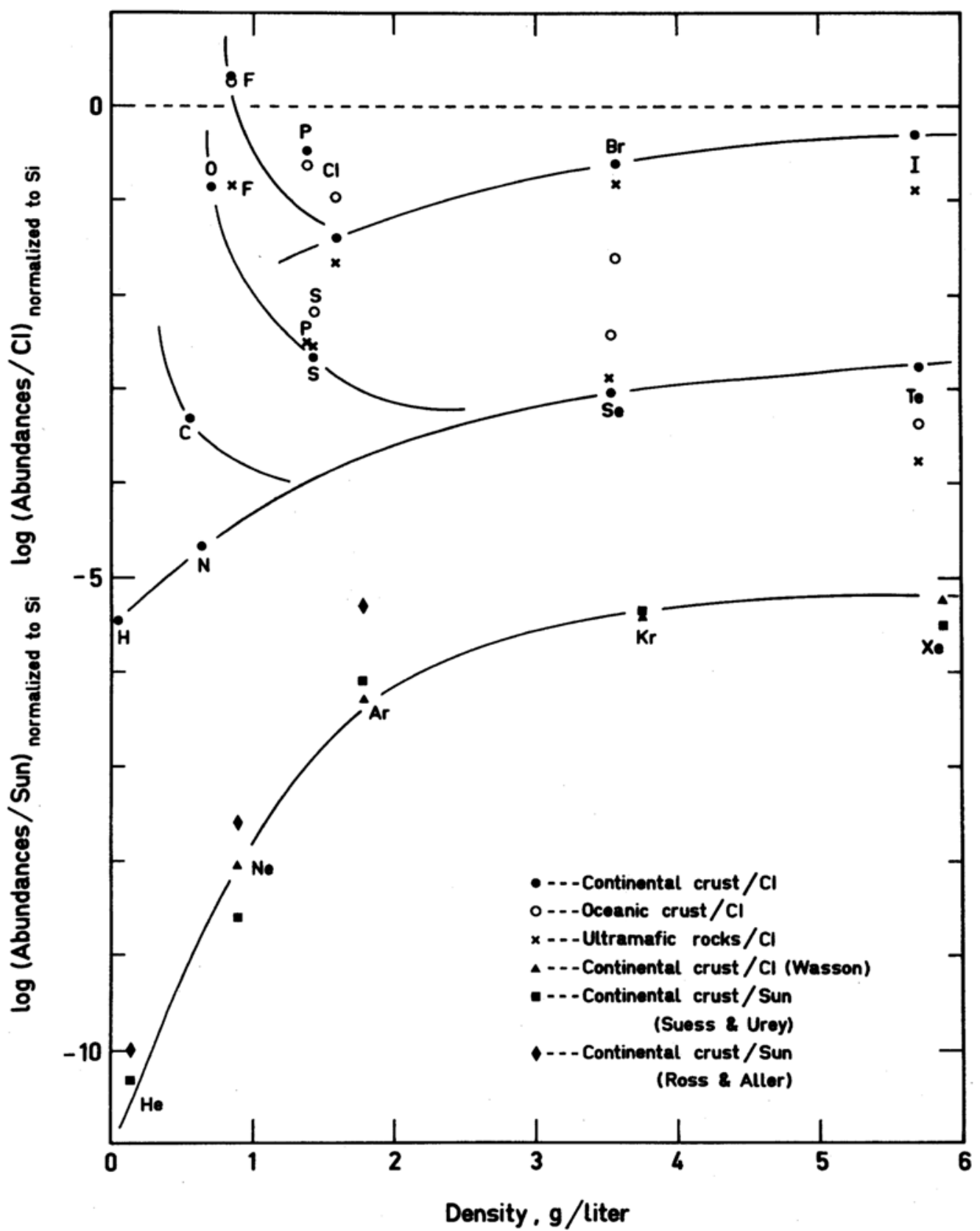

Fig. 4. Normalized abundances of the volatile elements in the crust and the ultramafics are plotted against the density for the assumed gaseous state of these elements at room temperature and atmospheric pressure. 
A few remarks for these elements are noted. First, with the only exception of $F$, the normalized abundance of these elements are all depleted by a few factors to several magnitudes relative to the primordial abundances according to both density and chemical affinities for various stable solids. The latter is related, to some extent, to the electronegativity of the elements. The inert gases possess the lowest chemical affinity, and they are depleted the most. The degree of depletion of these elements decreases with increasing density, as perhaps would be expected from kinetics of gases. There appears to be no competition between the two factors (density and chemical affinity) because the relative abundance among these inert gases is solely determined by their relative density.
The lines drawn in Fig. 4 are merely for convenience. The elements of Group VIIA are chemically most active of all, and thus they are least depleted. Here, however, the chemical affinity and the density are two competing factors. For the less active elements (I, Br and perhaps $\mathrm{Cl}$ ), density plays a decisive role, whereas the chemical affinity overwhelms the density for $\mathrm{F}$, which possesses the highest electronegativity and is chemically the most active element known. The elements of the VIA Group are chemically less active than those of the VIIA Group, and thus they are less abundant. The abundance pattern of these elements follows nearly that of the VIIA Group, but the density factor becomes less important than chemical affinity between Se and S. Oxygen possesses the

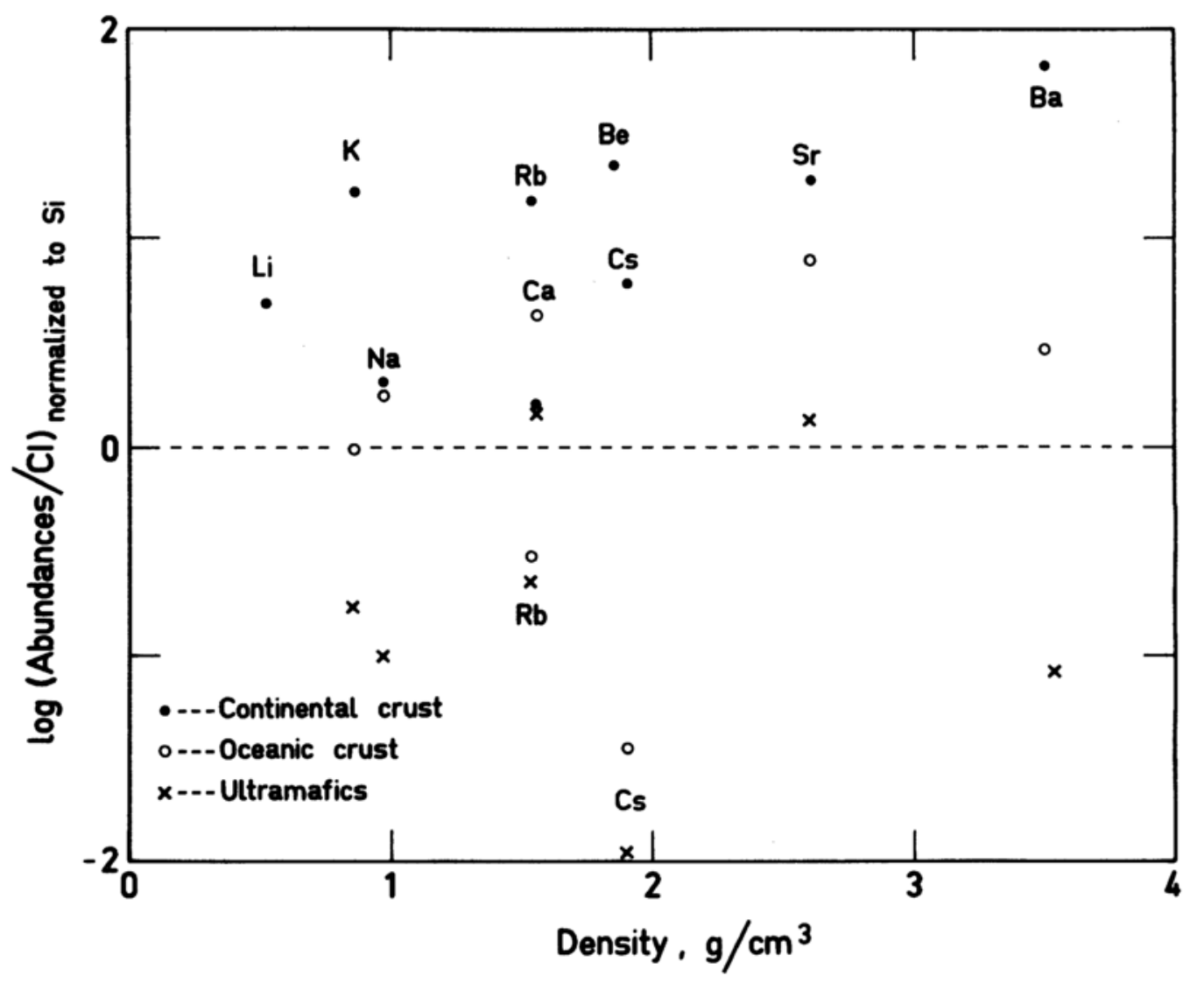

Fig. 5. Normalized abundances of the light elements in the crust and the ultramafics are plotted against the density of these elements at room temperature and atmospheric pressure. 
second highest value of electronegativity and is perhaps the second most active element known. Other volatile elements $(\mathrm{C}, \mathrm{H}, \mathrm{N}$, and $\mathrm{P}$ ) are rather irregular; their abundances, however, are most likely controlled by chemical affinity.

With the only exception of $\mathrm{P}$, there is no general trend which is observable for the abundances of these volatile elements in the continental crust, oceanic crust and the ultramafics. The difference in abundances between the different geological environments does not exceed one another by a factor greater than 10 . The abundance trend of $\mathrm{P}$ in the various environments approximates those of the light elements which is to be discussed.

Although it is mainly the chemical affinity which determines the relative abundances of these volatile elements in the Earth, the absolute abundances of these elements in the Earth are also controlled by their primordial abundances. On the basis of this study, it could perhaps be concluded that the Earth has retained all of its primordial complement of $\mathrm{F}$.

The normalized abundances $v s$. the densities of the light elements for the continental crust, oceanic crust and the ultramafics are shown in Fig. 5 (data sources have all been given before). Unlike the volatile elements, the normalized abundances of these elements in the continental crust are all enriched from a few factors to over 60 -fold relative to their primordial abundances. With the only exception of $\mathrm{Ca}$, the available data indicate that the abundances of the light elements all decrease in the following order: the continental crust, the oceanic crust and the ultramafics. The difference of abundances in the various geologic environments range from a factor over 10 to nearly 1,000 . The enrichment of $\mathrm{Ca}$ in the oceanic crust has been discussed by Lowengart (1975) and PyTKowicz (1979), and is likely due to perturbation by chemical affinity. For the elements of the same periodic Group, there is no clear trend between the abundance and the density of these elements. All these are characteristics for the light elements only, which are thus distinguishable from the volatile elements.
According to this study, the abundances of the light elements decrease, whereas those of the volatile elements remains nearly the same with increasing depth towards the center of the Earth. The mechanisms for the retention or enrichment of the volatile and the light elements in the Earth appear to be fundamentally different. The volatile elements are retained by chemical affinity and trapped in the Earth, and the light elements are primarily squeezed and then floated to the surface. This fundamental difference in mechanism is reflected in their abundance pattern.

It is not uncommon in the literature to find that the light elements of the IA Group are regarded as the volatile elements. Volatility strongly depends on the physical parameters of temperature and pressure. Should the bulk abundance of these light elements be depleted in certain compositional models of the Earth, the depletion might be attributed by the variations of temperature and pressure during the evolution of the Earth. It may be misleading, however, to classify them as volatile elements as indicated by their abundance pattern in the Earth's crust.

\section{Geological Classification of the Chemical Elements}

On the basis of previous discussion, it is perhaps timely to classify the chemical elements according to their abundance patterns and trends in the various geologic environments on the Earth's surface into the following four groups: heavy $(\mathrm{H})$, medial $(\mathrm{M})$, light $(\mathrm{L})$ and volatile (V) as shown in the Periodic Table (Table 2). The density of the elements in each group decreases generally in the same order. Note that the elements in the medial group are further divided into two sub-groups (MI and MII) occupying either side of the heavy elements in the Periodic Table. Although their densities are rather close, the general physical and chemical properties of these two sub-groups are somewhat different. Thus, the MI elements are slightly enriched whereas the MII elements are 
slightly depleted in the crust.

As mentioned previously, volatility depends strongly on both temperature and pressure. At sufficiently high temperatures, all the elements would become volatile, whereas pressure has an opposite effect. The geological classification of the chemical elements proposed in the present work is based mainly on the density and abundance data of the various chemical elements presently existing and observed on the Earth's surface. The Earth and many other extraterrestrial bodies suffered varying degrees of heating in the past, and the present. Assuming that these bodies were accreted from pre-existing planetesimals, the heat may have been generated by collision during accretion, by radionuclides with a short half-life (e.g. ${ }^{26} \mathrm{Al}$ ) during or after accretion, or both. Various elements would become volatile and tend to escape from the parent body when they were heated up to a sufficiently high temperature. The proportion of gaseous atoms and molecules of these volatile elements which would be retianed in the atmosphere around the parent body would depend on the strength of the gravitational field generated by the mass of the parent body (among other factors as well). The abundance of volatile elements retained in the parent body, along with all the remaining elements, would then be differentiated according to their densities in a gravity field. In other words, the primordial abundance of the elements in the solid body were primarily distributed according to volatility at high temperature, and then redistributed according to their density. During any stage of the above differentiation processes, however, the chemical affinity and mechanical processes (e.g. convection) would perturb the distribution of the chemical elements. For instance, $\mathrm{F}$ and $\mathrm{O}$ should be quite volatile elements, but most of them were retained in the parent body because of their strong chemical affinity for other elements to form stable dense phases; $\mathrm{C}$ should not be a volatile element, but its strong tendency to form gaseous $\mathrm{CO}$ and $\mathrm{CO}_{2}$ makes it become very volatile and consequently it is strongly depleted.

On the basis of the known physical and chemical properties and the observed abundances of the various chemical elements in the Earth's crust, it is proposed that at high temperatures the volatility of the lements among the various groups classified here decreases in the following order: volatile, medial (II), light, medial (I) and heavy. In the latter classification, according to volatility at high temperature, the heavy elements of the IB Group $(\mathrm{Cu}, \mathrm{Ag}$ and $\mathrm{Au}$ ) would belong to MII elements, as indicated by the heavy dashed lines in Table 2 . Among the light elements, the IA Group ( $\mathrm{Li}, \mathrm{Na}, \mathrm{K}, \ldots$ ) is more volatile than the IIA Group ( $\mathrm{Be}, \mathrm{Ca}$, $\mathrm{Sr}, \ldots$. . . The elements of MI and IIA Group are generally more enriched than those of the IA Group in the Earth's crust, despite the fact that densities of these elements increase in a reverse order (MI > IIA > IA) which suggest that the total resources of the IA Group elements of the Earth suffered a greater loss through volatilization during or after the formation of the Earth.

Thus, overall, the distribution of the chemical elements in the Earth and other planets was determined by processes more of a physical than a chemical nature.

\section{Alternative INTERPRETATION OF THE Abundance Pattern}

Unless one assumes that the abundance pattern of the distribution of chemical elements observed in the continental and oceanic crusts (Fig. 3) have always existed in their present form, in which case no specific interpretation of the evolution of the chemical abundances through geologic time would be required, the observed abundance pattern in the crust must inherit the bulk primordial abundance of the Earth and be perturbed by physical and chemical processes throughout the life of the Earth. GolDSCHMIDT (1937) and his earlier publications first attempted to offer a scientific interpretation of the abundance pattern of chemical elements on the Earth's surface. As briefly mentioned earlier, GoLDSCHMIDT's interpretation involves primarily processes of a chemical nature between the elements. Few quantitative data 
were available when he first proposed this concept. GoLDSCHMIDT had also recognised the difficulty of carrying out experiments in the laboratory to support his ideas. However, three compositional data sets which were available in support of the principles of the distribution of chemical elements were later put forward by him (e.g. GoLDSCHMIDT, 1937):

(a) Meteorites, in particular the iron meteorites.

(b) The Ovifak iron lumps from Disko Island, Greenland and the iron-nickel alloy of josephinite from Oregon, U.S.A.

(c) Certain metallurgical products from the copper industry of the Mansfeld district, Germany.

There is little doubt that emphasis on the occurrences places great weight on the distribution of "siderophile elements", in particular of the palladium and platinum families. GoLDSCHMIDT had accounted for the scarcity of these elements in the Earth's crust by a process of selective concentration into the Earth's interior, owing to the large chemical partitioning of these elements between silicates and iron alloys. Thus, a fundamental assumption in GolDschmIDT's ideas is that the materials of present crust and core were chemically equilibrated before the formation of the core. Should GolDSCHMIDT's principle for the distribution of chemical elements of the Earth's crust be correct, then the heterogeneous accretion theories regarding the formation of the Earth advocated by, e.g. EUCKEN (1944), TUREKIAN and ClaRK (1969), SMITH (1979) must be erroneous.

I feel, however, that the evidence presented by GOLDSCHMIDT for his principles of elemental distribution are questionable. First, the origin of meteorites is uncertain. The iron meteorites might have been derived from the iron core of a pre-existing planet or a large planetesimal. It has been suggested by WooD (1964) and GoLDSTEIN and SHORT (1967) that the iron meteorites may have been derived from the core of a parent body which is $250-300 \mathrm{~km}$ or less in radius. GoLDSTEIN and SHORT (1967) also suggested that more than one parent body may have been involved. Thus, the enrichment of the heavy elements in the iron meteorites may have been gravitationally carried out in precursor bodies before the iron meteorites were formed. On the other hand, MOREN and GolDSTEIN (1978) have argued that some iron meteorites may not have been formed within the core of a single parent body. The origin of both the Ovifak irons and the iron-nickel alloys of josephinite is a highly debatable subject at present. They might be of an extraterrestrial origin or might have been derived from the interior or the core of the earth. The latter origin has been suggested by e.g. UREY (1952) and recently advocated by BIRD and WEATHERS (1977, 1979). Of course, other types of terrestrial origin such as a chemical reduction cannot be totally ruled out. In addition, the data derived from metallurgical products can be accounted for by gravitational concentration as well. Thus, all the evidence used by GoLDSCHMIDT for this ideas of the geochemical distribution of the chemical elements can equally be used to support the hypothesis that gravitational differentiation of the chemical elements is important in the Earth. I do not, however, deny that the chemical affinity plays an important role in determining the distribution of the elements as well.

Severe difficulties are encountered if an interpretation of the elemental abundance pattern of the Earth's crust (Fig. 3) is based primarily on GoLDSCHMIDT's geochemical affinity principles. In order to account for the abundance pattern shown in Fig. 3, one might have to assume or to accept that the geochemical affinity between the heavy elements and iron decreases in the following order: the 6th Period (the platinum family), the 5th Period (the palladium family), and the 4th Period (Co, $\mathrm{Ni}$... ), and further assumes that the affinity of iron for these elements increases generally with increasing density for each given Period. Not only do these coincidences seem unlikely, but also the materials of the present crust (and the mantle too) and core of the Earth must be assumed to have been in equilibrium. There still exist problems, however, concerning the abundance patterns between the continental and 
oceanic crusts if the formation of the Earth's core is an once-for-all event, and the heavy elements were indeed extracted by chemical processes into the Earth's core before the formation of the crust.

Alternatively, one may assume that these heavy elements were enriched in the primordial abundances which were used to normalize the crust's abundance. In this case, one has to assume further that the abundances of these heavy elements in the primordial composition were enriched in the order: the 6th Period, the 5th Period, ... Thus, nearly all the difficulties of GoLDSCHMIDT's concept of the geochemical affinity would have also been encountered.

In conclusion, all these concepts attempting to account for the abundance pattern of the Earth's crust are not only incapable of achieving the desired effect but are also too restrictive. The simplest solution is that the chemical elements of the Earth's crust are gravitationally differentiated according to their density periodicity and are further perturbed by chemical affinities.

\section{IMPLICATIONS FOR \\ COSMOPHYSICAL ENVIRONMENTS}

After we have stablished that the distribution of chemical elements in the Earth's crust and its inferred interior is primarily controlled by the gravitational field, we have grounds for speculation on the nature of the physical environments for the extraterrestrial bodies that we have previously encountered in this study. If the present observation of the distribution of chemical elements in the Earth is correct, then one may infer that the chondrites were formed in an environment which has little or no influence of gravitation (or there exist some obstacles which prevent the chondrites from gravitational differentiation) whereas the achondrites were formed under the influence of gravitation (Fig. 2 ), and that the distribution of chemical elements in the Sun is not determined by its gravitational field (Fig. 1).

In the dynamic nuclear fusion process operative in the Sun, it is not surprising that the kinetic energy of the particles of chemical elements in the Sun overwhelms the influence of its gravitational field. Thus, the chemical elements in the outer layer, and perhaps the interior, of the Sun are not gravitationally differentiated.

The relative elemental abundances of the C3type carbonaceous chondrites and the ordinary chondrites shown in Fig. 2 suggest that the various types of chondrites may have suffered loss of their volatile elements, to various degrees, in their original orbits in space or when they were entering the Earth, or that the difference in their elemental abundances is indigenous. However, the very similar abundances of all the heavy elements in the different chondrites must reflect the fact that they could have escaped gravitational differentiation. This perhaps implies that their parent bodies are relatively small, that their parent bodies are large but with small density, and hence small gravitational field, or that there exist some obstacles which prevent their parent bodies from gravitational separation. The first two interpretations are preferred over the last one.

Two achondrites are shown in Fig. 2. Unfortunately, the data for the heavy elements of the fifth Period (the palladium family) are not available for these achondrites. The heavy elements and their adjacent neighbours of the fourth and sixth Periods were connected by solid and broken lines in Fig. 2. Johnstown (Ah) indicates strong characteristics of gravitational differentiation whereas Havero (Au) seems to be only slightly modified by gravitation.

The parent bodies for chondrites and achondrites thus appear quite different. The chondrites may well represent remnant planetestimals which aggregated to form the Sun and planets. The other meteorite types may represent the various portions of a fragmented planet which has been differentiated both physically and chemically from materials of chondritic composition. Our interpretation of the physical environment for the meteorites on the basis of their abundance pattern of the chemical ele- 
ments is in line with the general concepts regarding the origin of meteorites outlined by, e.g. MASON (1962) and WASsON (1974), or of asteroids by e.g. Chapman (1981). On the other hand, the observation of the abundance patrern of chemical elements in this study may be used as evidence in support of these models of the origin of meteorites and asteroids.

Acknowledgements $-\mathrm{I}$ am indebted to R. J. ARCULUS, W. A. BASSETT and S. R. TAYLOR for their critical review and comnents. However, imperfections and impossibilities in the paper are solely my responsibility.

\section{REFERENCES}

ANDERSON, D. L. (1975) Chemical plumes in the mantle. Geol. Soc. Amer. Bull. 86, 1593-1600. BENCE, A. E., GROVE, T. L., PAPIKE, J. J. and TAYLOR, S. R. (1981) Basalts as probes of planetary interiors: constraints from major and trace element chemistry, in Basaltic volanism on the terrestrial planets. Pergamon Press, N.Y., 311-339.

BIRD, J. M. and WEATHERS, M. S. (1977) Native iron occurrences of Disko Island, Greenland. J. Geol. 85,359-371.

BIRD, J. M. and WEATHERS, M. S. (1979) Origin of josephinite. Geochem. J. 13, 41-55.

CAmeron, A. G. W. (1973) Abundances of the elements in the solar system. Space Sci. Rev. 15, 121-146.

CHAPMAN, C. R. (1981) Asteroids, in The new solar system. Editors J. K. BEATTY, B. O'LEARY and A. ChaIkIn, Sky Publishing Co., Cambridge, Mass. \& Cambridge Univ. Press, London, 97-104.

CHOU, C-L. (1978) Fractionation of siderophile elements in the Earth's upper mantle. Proc. Lunar Planet. Sci. Conf. 9th, 219-130.

ClAYTON, R. N. (1978) Isotopic anomalies in the early solar system. Ann. Rev. Nucl. Sci. 28, 501522.

CLAYTON, R. N. (1981) Isotopic variations in primitive meteorites. Phil. Trans. R. Sco. London A303, 339-349.

CRocket, J. H. (1981) Geochemistry of the platinum-group elements, in Platinum-group elements: Mineralogy, geology, recovery. Editor L. J. CABRI, Harpell's Press, Quebec, 47-64.

EUCKEN, A. (1944) Physikalisch-chemische Betrachtungen über die früheste Entwicklungsgeschichte der Erde. Nachr. Akad. Wiss. Göttingen, Math. Phys. Kl. 1,1-25.

GolDSCHMIDT, V. M. (1922) Der Stoffwechsel der
Erde. Vidensk. Skr. I, Math-naturv. K1. No. 11, 25pp.

GoLDSCHMIDT, V. M. (1923) Geochemische Verteilungsgesetze der Elemente. Vidensk. Skr. I. Math.inaturv. Kl. No. 3, $17 \mathrm{pp}$.

GoLDSCHMIDT, V.M. (1937) The principles of distribution of chemical elements in minerals and rocks. $J$. Chem. Soc. London, 655-673.

GoldSCHMIDT, V. M. (1954) Geochemistry. Clarendon Press, Oxford, 730pp.

GOLDSTEN, J. I. and SHORT, J. M. (1967) The iron meteorites, their thermal history and parent bodies. Geochim. Cosmochim. Acta 31, 1733-1770.

GoLES, G. G. (1967) Trace elements in ultramafic rocks, in Ultramafics and related rocks. Editor P. J. WYLLIE, John Wiley and Sons, New York, 352-362.

HAKLI, T. and WRIGHT, T. L. (1967) The fractionation of nickel between olivine and augite as a geothermometer. Geochim. Cosmochim. Acta 31, 877884.

HEDGE, C. E. (1971) Nickel in high-alumina basalts. Geochim. Cosmochim. Acta 35, 522-524.

Hertogen, J., JANSSENS, M-J. and PALME, H. (1980) Trace elements in ocean ridge basalt glasses: implications for fractionations during mantle evolution and petrogenesis. Geochim. Cosmochim. Acta 44, 21252143.

HOLWEGER, H. (1977) The solar $\mathrm{Na} / \mathrm{Ca}$ and $\mathrm{S} / \mathrm{Ca}$ ratios: a close comparison with carbonaceous chondrites. Earth Planet. Sci. Lett. 34, 152-154.

Jagoutz, E., Palme, H., Baddenhausen, H., Blum, K., Cendales, M., Dreibus, G., Spettel, B., LORENZ, V. and WÄNKE, H. (1979) The abundances of major, minor and trace elements in the Earth's mantle as derived from primitive ultramafic nodules. Proc. Lunar Planet. Conf. 10th, 20312050.

LEEDS, A. R., KNOPOFF, L. and KAUSEL, E. G. (1974) Variations of upper mantle structure under the Pacific Ocean. Science 186, 141-143.

LIU, L. (1973) Correlation of density periodicity of pressure-induced polymorphic transformations in solid elements. J. Appl. Phys. 44, 2470-2474.

LIU, L. (1982) The "F" zone. Geophys. Res. Lett. 9, 808-811.

LOWENGART, S. (1975) The abnormal distribution of calcium between the crust as a whole and the sediments. Israel J. Earth Sci. 24, 15-18.

MASON, B. (1962) Meteorites. John Wiley \& Sons, New York, 274pp.

MASON, B. (1966) Principles of geochemistry. John Wiley \& Sons, New York, 329pp.

Mason, B. (1979) Cosmochemistry, Part I. Meteorites. U.S. Geol. Survey. Prof. Paper 440-B-1, U.S. Government Printing Office, Washington, 132pp. 
MOORE, J. G. and FABBI, B. P. (1971) An estimate of the juvenile sulfur content of basalt. Contr. Mineral. Petrol. 33, 118-127.

MOREN, A. E. and GoldsteIn, J. I. (1978) Cooling rate variations of group IVA iron meteorites. Earth Planet. Sci. Lett. 40, 151-161.

MORGAN, W. J. (1972) Deep mantle convection plums and plate motions. Am. Assoc. Petrol. Geol. Bull. 56, 203-213.

Morgan, J. W., Wandless, G. A., Petrie, R. K. and IRVING, A. J. (1981) Composition of the Earth's upper mantle - I. Siderophile trace elements in ultramafic nodules. Tectonophysics 75, 47-67.

NABELEK, P. I. (1980) Nickel partitioning between olivine and liquid in natural basalts: Henry's law behaviour. Earth Planet. Sci. Lett. 48, 293-302.

PYTKOWICZ, R. M. (1979) Excess crustal calcium problem. Geochem. J. 13, 15-17.

RINGWOOD, A. E. and Kesson, S. E. (1977) Basaltic magmatism and the bulk composition of the Moon. II. siderophile and volatile elments in Moon, Earth and chondrites: implications for lunar origin. Moon $16,425-464$.

RonOV, A. B. and YARoshevsKIY, A. A. (1976) A new model for the chemical structure of the Earth's crust. Geochem. Int. 13, 89-121.

Ross, J. E. and Aller, L. H. (1976) The chemical composition of the Sun. Science 191, 1223-1229.

SHAw, D. M. (1972) Development of the early continental crust. I. use of trace element distribution coefficient models for the protoarchean crust. Can. J. Earth Sci. 9, 1577-1595.

SMITH, J. V. (1977) Possible controls on the bulk composition of the Earth: implications for the origin of the Earth and Moon. Proc. Lunar Planet. Conf. 8th, 333-369.
SMITH, J. V. (1979) Mineralogy of the planets: a voyage in space and time. Mineral Mag. 43, 1-89.

SUESS, H. E. and UREY, H. C. (1956) Abundances of the elements. Rev Mod. Phys. 28, 53-74.

SUN, S. S. and HANSON, G. N. (1975) Evolution of the mantle: geochemical evidence from alkali basalt. Geology 3, 297-302.

TAYlor, S. R. KaYe, M., White, A. J. R., DUnCan, A. R. and EWART, A. (1969) Genetic significance of $\mathrm{Co}, \mathrm{Cr}, \mathrm{Ni}, \mathrm{Sc}$ and $\mathrm{V}$ content of andesites. Geochim. Cosmochim. Acta 33, 275-286.

TAYLOR, S. R. (1980) Refractory and moderately volatile element abundances in the Earth, Moon and meteorites. Proc. Lunar Planet. Sci. Conf. 11th, 333-348.

TAYLOR, S. R. and MCLennan, S. M. (1981) The composition and evolution of the continental crust: rare earth element evidence from sedimentary rocks. Phil. Trans. R. Soc. London A 301, 381-399.

TUREKIAN, K. K. and ClARK, S. P., JR. (1969) Inhomogeneous accumulation of the Earth from the primitive solar nebula. Earth Planet. Sci. Lett. 6, 346-348.

TUREKIAN, K. K. and WEDEPOHL, K. H. (1961) Distribution of the elements in some major units of the Earth's crust. Geol. Soc. Am. Bull. 72, 175-191.

UREY, H. C. (1952) The planets: Their origin and development, Yale Univ. Press, New Haven, 245pp.

WASsON, J. T. (1974) Meteorites. Springer-Verlag, New York, 316pp.

WILSON, J. T. (1973) Mantle plumes and plate motions. Tectonophysics 19, 149-164.

WoOD, J. A. (1964) The cooling rates and parent planets of several iron meteorites. Icarus 3, 429459. 